INTERNATIONAL JOURNAL OF RESEARCHES IN BIOSCIENCES, AGRICULTURE AND TECHNOLOGY (c) VISHW ASHANTI MULTIPURPOSE SOCIETY (Global Peace Multipurpose Society) R. No. MH-659/13(N) www.vmsindia.org

\title{
KNOWLEDGE, ATTITUDE AND PRACTICE STUDY OF PREGNANT WOMEN REGARDING ANEMIA
}

\author{
Rachana M. Sirsat ${ }^{1}$ and Ankush M. Sirsat ${ }^{2}$ \\ ${ }_{1}$ Bhartiya Mahavidyalaya, Amravati, \\ ${ }^{2}$ Me dical Officer, Le prosy, Amravati.
}

\begin{abstract}
:
Anemia in pregnancy is one of the leading cause of morbidity and mortality for both antenatal mothers and the newborns. Howe ve $\mathrm{r}$ early diagnosis, effective treatment and prope $\mathrm{r}$ counseling can reduce the morbidity of a nemia in both. Hence, this study was carried out o study the knowledge, attitude and practices of pregnant women regarding anemia in Amravati (M.S). About 187 primigravida age more than 19 years visiting the OBGY OPD (Antenatal OPD) in a te rtiary hos pital over a period of 4 months from January 2016 to April 2016 were selected by systematic random sample method and were asked to fill a questionnaire regarding anemia to test their knowledge, attitudes and practices related to anemia such as information about iron rich dietary sources, maternal and fe tal complications of ane mia, source of knowledge, implementation of iron rich diet, drug compliance etc and data was collected accordingly. $104(55.61 \%)$ mothers out of 187 were aware of the dietary sources of iron however only 66 $(63.46 \%)$ women actually imple mented this in their diet practice. About $79(42.24 \%)$ mothers were aware of some of the maternal complications of anemia in pregnancy. $33(41.77 \%)$ of them knew about fetal complications like low birth weight. Source of this knowledge was TV and radio for majority of women. Only 11 mothers were showing poor compliance to iron medication. The study reflects the ignorance, poverty and illiteracy among majority of the antenatal women coming to the Hos pital. Assess ments of knowle dge and practice and implication of health education are necessary for pre vention of Anemia in pregnancy. Educating antenatal women about the importance of diet and implementing this into practice will definitely help in the prevention of ane mia and its consequences on health.
\end{abstract}

Key words: Anemia, Primigravida, Antenatal, Knowledge, Attitude, Practice.

\section{Introduction:}

Anemia in pregnancy is one of the leading cause of maternal and perinatal morbidity and mortality. WHO has es timated that the prevalence of ane mia among pregnant wo men is $14 \%$ in developed countries and $51 \%$ in developing countries. In India, about $64 \%$ pregnant women are affected with anemia. Inspite of improved awareness among the community and improved health care services, anemia continues to kill the mothers every year. Thus, early detection and prompt treatment of anemia in Pregnancy is a mandatory step to be followed strictly at all levels of health care services in order to prevent maternal and pe rinatal morbidity and mortality.

Objective : To study the knowled ge, attitude and practices of pregnant women regarding ane mia in a tertiary hospital, Amravati (M.S).

\section{Method :}

Study type: Cross sectional

Study area: Tertiary care Hospital, Amravati (M.S)

Study period: 4 months (January 2016 to April 2016)

The study was carried out on 187 primig ravida visiting the tertiary hospital over a period of 4 months from January 2016 to April 2016. First, permission of Hospital Ethical Committee was take $n$ and then women attending the OBGY OPD (Antenatal OPD) at a tertiary hospital were selected by sys te matic random sample method and were asked to fill a questionnaire re garding anemia to test their knowledge, attitudes and practices related to anemia such as information about iron rich dietary sources, maternal and fetal complications of anemia, source of knowledge, implementation of iron rich diet, drug compliance etc and data was collected accordingly. Descriptive and inferential statistics was used to analyze the data.

Inclusion criteria: Primigravida, age $>19$ years Results :

The following data was obtaine $d$ from the prese $n t$ study:

Majority of the women, 103 out of 187 (55.08\%) belonged to 19 to 25 years age group. 57 (30.48\%) women belonged to the 26 to 30 years age group and $27(14.43 \%)$ women belonged to > 30years age group (Figure 1).

Out of the 187 women included in the study, 92 $(49.19 \%)$ belonged to lower socio economic status, 59 (31.55\%) belonged to the upper lower class, 29 (15.50\%) belonged to the lower middle class and $7(3.74 \%)$ to upper middle class (Table $1)$. 
Table 1: The socio economic status of the antenatal women.

\begin{tabular}{l|l|}
\hline $\begin{array}{l}\text { Socioeconomic } \\
\text { status }\end{array}$ & $\begin{array}{l}\text { No. of antenatal } \\
\text { women }\end{array}$ \\
\hline Lower & $\mathbf{9 2}$ \\
\hline Upper lower & $\mathbf{5 9}$ \\
Lower middle & $\mathbf{2 9}$ \\
\hline Upper middle & $\mathbf{7}$ \\
\hline
\end{tabular}

Table 2: The number of antenatal women and the trimester in which they first reported to the hospital.

\begin{tabular}{l|c|}
\hline $\begin{array}{l}\text { Trimester of } \\
\text { Pregnancy }\end{array}$ & $\begin{array}{c}\text { No. of antenatal } \\
\text { women }\end{array}$ \\
\hline First & $\mathbf{5 5}$ \\
\hline Second & $\mathbf{1 0 1}$ \\
\hline Third & $\mathbf{3 1}$ \\
\hline
\end{tabular}

About 55 (29.41\%) patients registered in the first trimester, $101 \quad(54.01 \%)$ patients registered in the second trimester and 31 $(16.57 \%)$ patients registered in the third trime ster (Table 2).

$104(55.61 \%)$ women were aware of the food items which were a rich source of iron, however only 66 (63.46\%) of them implemented these food items in their daily diet. Only 79 (42.24\%) women were aware of a few maternal complications of anemia like PPH, failing lactation, recurrent infections etc and only 33 $(41.77 \%)$ of them were aware of fetal complications like IUGR, infections leading to pre te rm labour. Only 11 (5.88\%) women we re not compliant to the iron medication. (Fig 2)

Out of 187 women, About 117 (62.56\%) women said that all the knowledge they had, was imparted to the m by TV or Radio, 49 (26.20\%) attributed it to friends and relatives while the remaining $21(11.22 \%)$ got it via books and newspaper. (Fig 3)

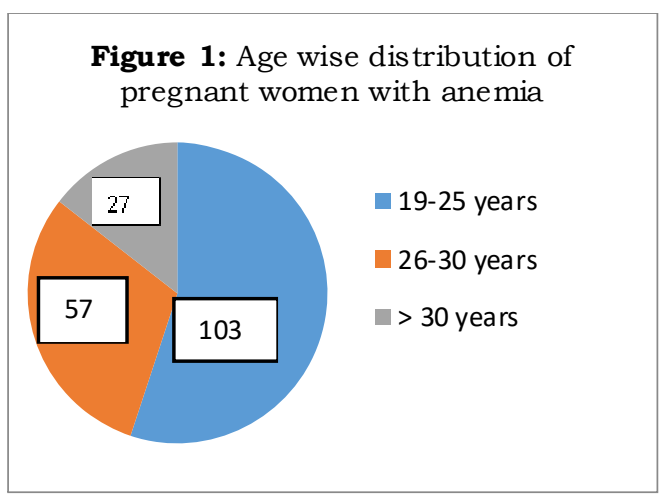

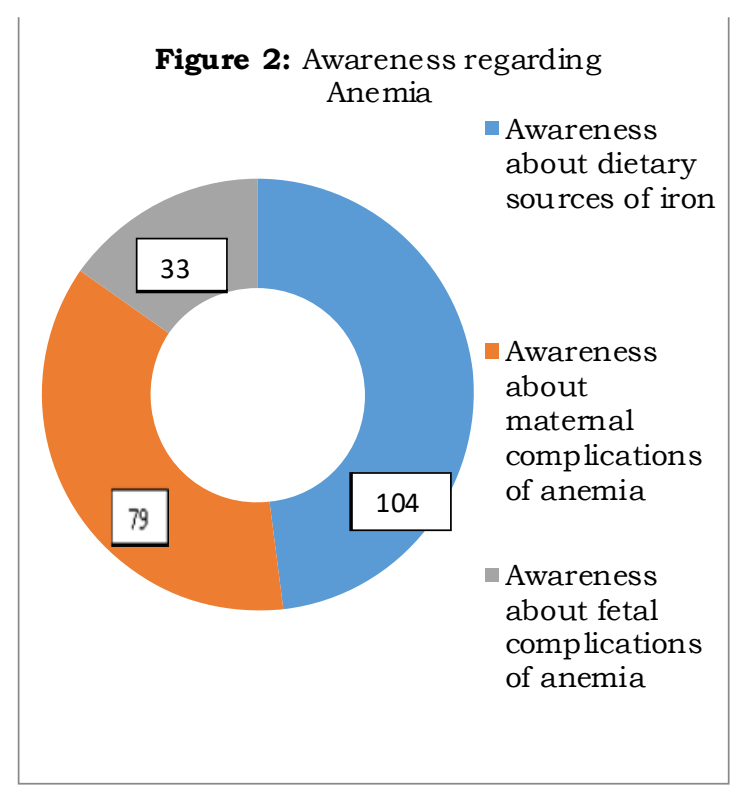

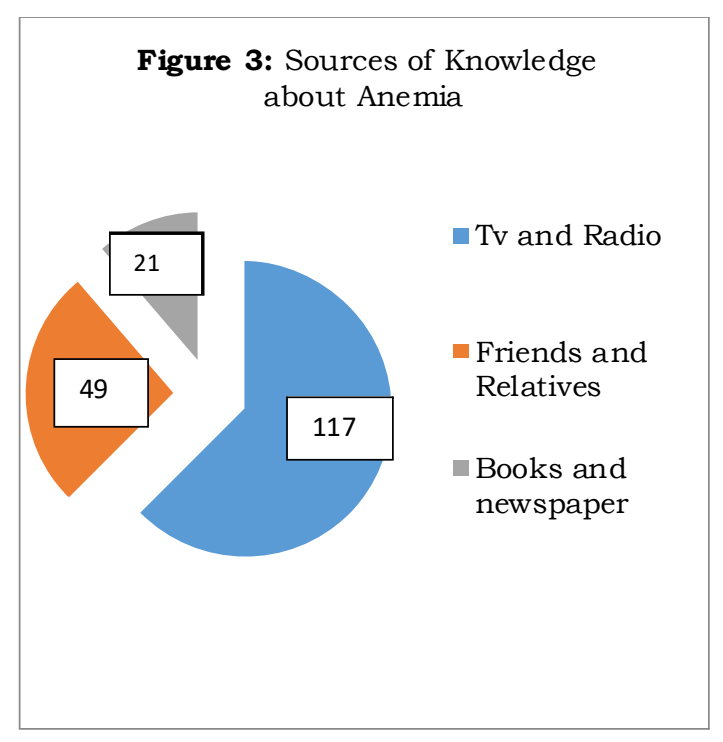

\section{Discussion :}

Anemia is a major \& significant public health problem throughout the world, particularly for women of reproductive age in developing countries. In India anemia is a leading cause of maternal morbid ity and mortality $\&$ it has se rious consequences on fetal health also. A significant association of anemia with socioeconomic status \& educational status indicates a strong need to develop strategies for effective adult education and to improve the socio economic status of the population. A study by Raksha $\mathrm{M}$ and others (2016) drew the same conclusion. 
The present study highlighted the importance of providing information to all the antenatal women in the clinics regarding prevention of anemia in pregnancy. The study also reflects the ignorance about imple mentation / addition of iron rich food in the diet inspite of having knowledge about the source of iron rich food. This is similar to the findings of Maj Sivapriya S and others (2015).

There should be effective mandatory preconception and ante natal counselling of the antenatal women to identify the risk factors in pregnancy $\&$ to reduce the enormous burden of anemia in pregnancy. This is in line with the findings of Dorairajan Gowari and others (2017).

\section{Conclusion :}

Present study supports the conclusion that educating antenatal women about the importance of diet and implementing this into practice will help in the prevention of anemia. There should be mandatory preconception and antenatal counselling sessions for the women to identify the risk factors in pregnancy and to reduce the enormous burden of anemia in pregnancy. Doctors, Nurses and other health workers may bring about a significant change in these women in their nutritional habits, ensuring early registration and regular follow up which will ultimately help in reducing the incidence of anemia.

\section{References :}

Sivapriya SM, Parida L. (2015). A study to assess the knowledge and practices regarding prevention of anemia among antenatal women attending a tertiary level hospital in Pune. IJSR NET 4(3):12 10-14.

Kulkarni KK. (2015). KAP study among Indian antenatal women: can we reduce the incide nce of anemia? The J Obste tr Gynecol India,65(5):3202 .

Dorairajan G, Palanivel C, Sakthi D. (2014). Influence of awareness and attitude about anemia and iron supplements on prediction of anemia among pregnant women. BJOG, 121:153-76.

Rizvi F. Impact of maternal education, and socioeconomic status on maternal nutritional knowledge and practices regarding iron rich foods and iron supplements. (2012). Ann Pak Inst Med Sci, 8(2):101-5.

Benoist DB, Mclean E, Egli I, Cogswell M. (2008). Worldwide prevalence of anemia 19932005: WHO Global Database on Anemia.

Khan KS, Wojdyla D, Say L, Gülmez oglu AM, Van Look PF. (2006). WHO analysis of cau ses of maternal death: a systematic review. Lancet, 367:1066-74.

Alam AY, Qureshi AA, Adil MM, Ali H. (2005). Comparative study of knowledge, attitude and practices among antenatal care facilities utilizing and non-utilizing women. J Pak Med ASSoc, 55(2):53-6. 